\section{International Journal of Medical Research and Review}

\title{
Posterior segment intraocular foreign body with secondary retinal detachment in a phakic eye: a case report
}

\section{Porwal A. ${ }^{1}$, Jain $\mathrm{H}^{2}{ }^{2}$, Mahajan P. ${ }^{3}$}

DOI: https://doi.org/10.17511/ijmrr.2020.i05.06

1* Amit C Porwal, Senior Consultant Cataract and Head Glaucoma Services, Department of Glaucoma, Choithram Netralaya, Indore, Madhya Pradesh, India.

2 Hardik Jain, Consultant Ophthalmologist, Department of Retina, Choithram Netralaya, Indore, Madhya Pradesh, India.

3 Pratik Mahajan, Consultant Ophthalmologist, Department of Retina, Choithram Netralaya, Indore, Madhya Pradesh, India.

Intraocular foreign bodies (IOFBs) are an important cause of visual loss. The current case describes a case of retained intraocular foreign body with secondary retinal detachment in a phakic eye in a 38-year-old man. The foreign body was safely removed through the sclerotomy port without touching the crystalline lens. The current case report wanted to show the anatomic and visual outcomes of vitreoretinal surgery in such cases.

Keywords: Intraocular foreign body, Retinal detachment, Phakic eye, Visual loss, Visual trauma

Corresponding Author

Amit C Porwal, Senior Consultant Cataract and Head Glaucoma Services, Department of Glaucoma, Choithram Netralaya, Indore, Madhya Pradesh, India. Email: amitcporwal@gmail.com
How to Cite this Article

To Browse

Porwal AC, Jain H, Mahajan P. Posterior segment intraocular foreign body with secondary retinal detachment in a phakic eye: a case report. Int J Med Res Rev. 2020;8(5):375-378.

Available From

https://ijmrr.medresearch.in/index.php/ijmrr/article/ view/1217

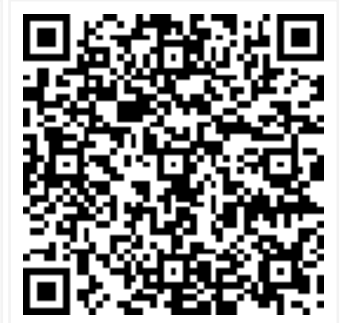

Review Round 3

Review Round 2

2020-10-01

Ethical Approval

Yes
Plagiarism X-checker

$$
5 \%
$$

Accepted 2020-10-06

Note 


\section{Introduction}

Intraocular foreign bodies (IOFB) are present in up to $40 \%$ of cases with ocular trauma [1]. Foreign body (FB) can lodge in the anterior or posterior segment of the eye depending upon the nature of the injury, site of entry, and velocity of a foreign body. The most common causes of IOFB include hammering (60-80\%).

The management of IOFB depends on clinical assessment and examination. Visual recovery after ocular trauma also depends on the involvement of the retina. In this case report, the current experience was shared with advances in the surgical technique for removal of retained posterior segment IOFB with significant improvement in prognosis.

\section{Case Report}

A 38-year-old man came with complaints of painless, gradual diminution of vision in the left eye for 2 months. The patient gave a history of trauma to the left eye during welding approximately 2 years back. He has not felt any discomfort for all this time; therefore he did not refer to an ophthalmologist.

On examination, visual acuity in the right eye was counting finger 1 meter due to nebulo-macular corneal opacity of size $4.5 \times 5 \mathrm{~mm}$ covering pupillary area since childhood and counting finger 4 meters in the left eye. The intraocular pressure was determined $11 \mathrm{mmHg}$ and $12 \mathrm{mmHg}$ in the right and left eye, respectively. The evaluation of the relative afferent pupillary defect was negative.

On slit-lamp examination of the left eye, there was a healed corneal scar at 3'o clock hour position and an entry wound noted on the iris at the 3' o clock hour position (Figure 1 ). There was no sign of infection probably due to the inert nature of the foreign body entered. The lens showed no cataractous changes.

The fundus examination revealed an intraocular foreign body at posterior pole 2-3 disc diameter from fovea with an inferior retinal detachment was seen (Figure 2). X-ray orbit was advised which revealed a radiopaque foreign body in the left eye/orbit (Figure 3).

Left eye optical coherence tomography showed detachment of the inner retinal layer from the outer retinal pigment epithelium (Figure 4).
The patient was advised to undergo vitrectomy with FB removal and silicone oil injection. 23 gauge Pars plana vitrectomy was performed. After removing the posterior hyloid, perfluorocarbon liquid was injected to stabilize and assess the posterior pole.

Scleral entry was enlarged by a 20 gauge MVR blade and the foreign body was grasped and removed through the scleral port with the intraocular forceps. Fluid-air exchange was done and the site of the foreign body was used as retinotomy to drain the subretinal fluid. Endolaser was done around it. Silicone oil infusion was done and the ports were sutured. The immediate post-operative period was uneventful.

At one week follow up, the retina was well settled. The patient was advised to maintain a prone position and routine post-operative medication was prescribed. A one-month, follow-up retina was attached and laser mark was seen and visual acuity improved to 6/60. (Figure 5).

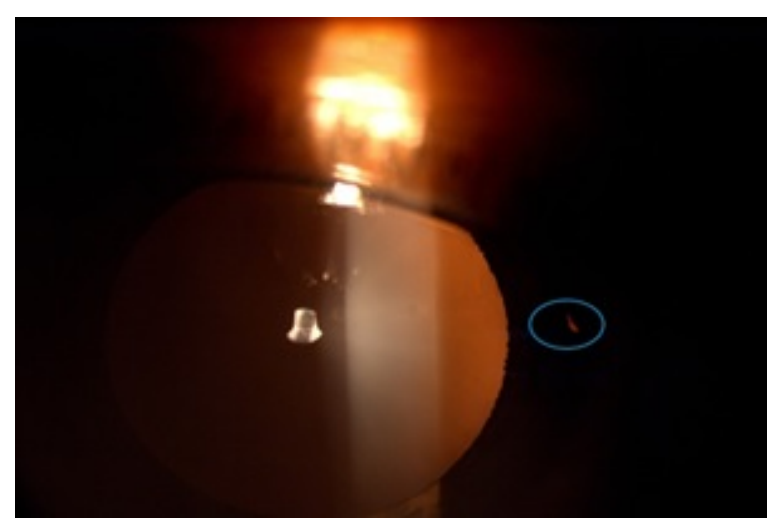

Fig-1: Defect on iris through retro illumination on slit-lamp examination of LE.

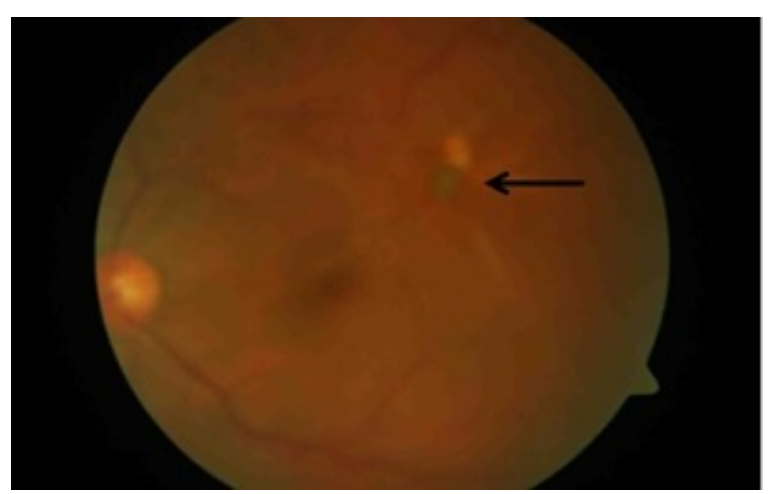

Fig-2: Clinical fundus image of the left eye showing foreign body at the posterior pole and inferior retinal detachment (arrow). 


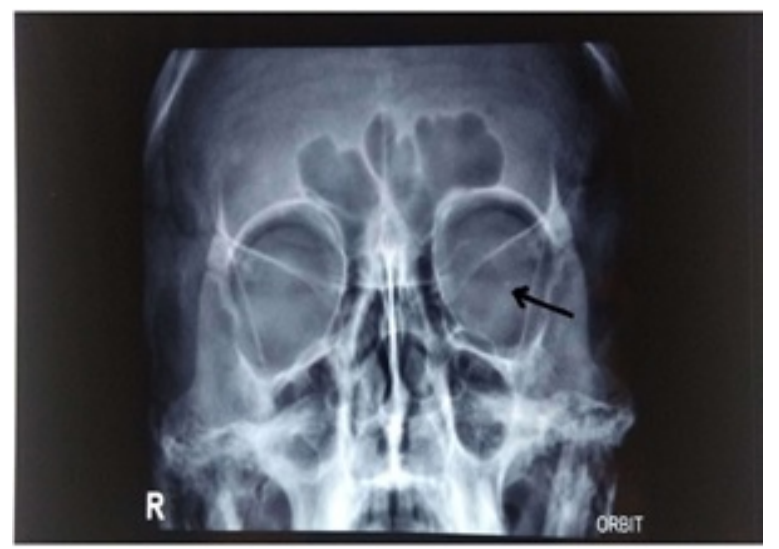

Fig-3: Orbital radiography anteroposterior view of LE showing intraocular foreign body (arrow).
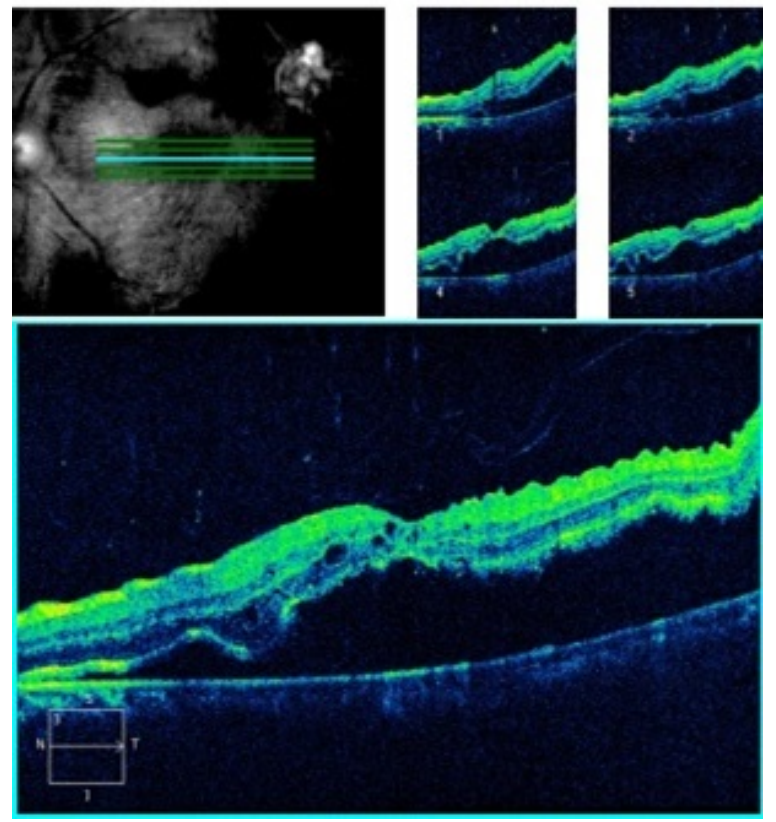

Fig-4: LE OCT showing detachment of the inner retinal layer from the outer retinal pigment epithelium.

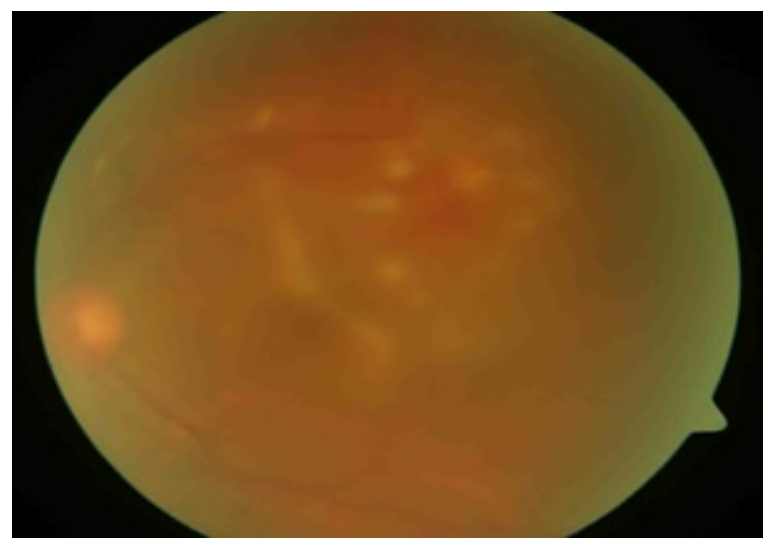

Fig-5: Appearance of left eye after endolaser photocoagulation (postoperative day $\mathbf{3 0}$ ).

\section{Discussion}

Intraocular foreign bodies are frequently encountered in clinical practice $[2,3]$. High velocity, relatively small particles are the most common foreign bodies found in the eye. A detailed history is important to determine the time of injury, mode of injury, and the composition of the expected IOFB [4]. Special emphasis should be given to the decision about proper surgical planning. The prognosis depends on a lot of factors including the type of foreign body, whether metallic or inert, the size of foreign body and the location inside the eye, presence of other complications such as retinal detachment, the availability of modern surgical instrumentation, and the expertise of the surgeon [5].

No signs of any anterior or posterior chamber reaction were noted owing to the inert nature of the IOFB, presuming it to be hot at the time of entry (as it entered at the time of welding). Computed tomography (CT scan) of the orbit is an ideal imaging method for the diagnosis of IOFB's. As the intraocular foreign body was visible at the posterior pole and looking at poor socio-economic condition CT scan was not advised but other radiograms such as X-ray, ultrasound were performed because they are very accurate in diagnosing the presence of the IOFB.

Pars plana vitrectomy (PPV) is the preferred technique to remove IOFBs from the posterior segment [6]. Due to the complexity of these cases, PPV with silicone oil tamponade as the primary surgical technique has opted. Simona Delia Nicoara et al showed poor visual outcomes of IOFB with retinal detachment in their study [7]. Thus, this case shows that a good prognosis can be achieved in cases of posterior pole IOFB with retinal detachment, after the meticulous vitreoretinal procedure despite the complexity of the IOFB position.

\section{Reference}

01. Parke DW 3rd, Flynn HW Jr, Fisher YL. Management of intraocular foreign bodies- a clinical flight plan. Can J Ophthalmol. 2013;48(1)8-12.

doi: $10.1016 /$ j.jcjo.2012.11.005 [Crossref] 
02. Duke Elder S. System of Ophthalmology. St Louis, CV Mosby Co. 1972;14(1)508-543,560564.

[Crossref]

03. Bryden FM, Pyott AA, Bailey M, McGhee CN. Real time ultrasound in the assessment of intraocular foreign bodies. Eye (Lond). 1990;4(Pt-5)727-731.

doi: $10.1038 /$ eye.1990.103 [Crossref]

04. Williams DF, Mieler WF, Abrams GW, Lewis $H$. Results and prognostic factors in penetrating ocular injuries with retained intraocular foreign bodies. Ophthalmol. 1988;95(7)911-916.

doi: $10.1016 / \mathrm{s} 0161-6420(88) 33069-1 \quad$ [Crossref]
05. Parke DW 3rd, Flynn HW Jr, Fisher YL. Management of intraocular foreign bodies- $a$ clinical flight plan. Can J Ophthalmol. 2013;48(1)8-12.

doi: $10.1016 /$ j.jcjo.2012.11.005 [Crossref]

06. Weichel LT, Yeh S. Techniques of intraocular foreign body removal. Tech Ophthalmol. 2008;6(3)88-97.

doi: 10.1097/ITO.0b013e318188e459 [Crossref]

07. Nicoară SD, Irimescu I, Călinici T, Cristian C. Intraocular foreign bodies extracted by pars plana vitrectomy- clinical characteristics, management, outcomes and prognostic factors. BMC ophthalmol. 2015;15(1)151.

doi: $10.1186 / \mathrm{s} 12886-015-0128-6 \quad$ [Crossref] 